\title{
$H$. pylori and mitochondrial changes in epithelial cells. The role of oxidative stress
}

\author{
M. Calvino-Fernández and T. Parra-Cid \\ Unidad de Investigación. Hospital Universitario de Guadalajara. Centro de Investigación Biomédica en Red de \\ Enfermedades Hepáticas y Digestivas (CIBERehd). Spain
}

\begin{abstract}
Infection with $H$. pylori plays a role in the pathogenesis of gastritis, peptic ulcer, gastric carcinoma, and gastric lymphoma, but mechanisms leading to the various clinical manifestations remain obscure and are the primary focus of research in this field.

Proliferation and apoptosis are essential in the maintenance of gastric tissue homeostasis, and changes seen in their balance may condition gastric mucosal changes during infection. Thus, excessive apoptosis or proliferation inhibition will result in cell mass loss, which is observed in gastric ulcers. On the other hand, accelerated epithelial cell turnover is characteristic of carcinogenic mucosas.

There is also scientific evidence that demonstrates an association between $H$. pylori infection and exacerbated synthesis of free radicals, the latter being well known as a primary cause of cell death.

A thorough review of the literature and the results of our experimental research lead to conclude that $H$. pylori-induced oxidative stress activates the intrinsic pathway of apoptosis. Structural and functional changes caused by this process on mitochondrial organelles lie at the origin of gastric mucosal toxicity, and lead to the development of the various manifestations associated with this infection. Based on these data we suggest that therapy with antioxidants should prove beneficial for the clinical management of patients with $H$. pylori infection.
\end{abstract}

Key words: Helicobacter pylori. Oxidative stress. Apoptosis. Mitochondria.

\section{INTRODUCTION}

Helicobacter pylori (H. pylori) is a gram-negative, extracellular, microaerophilic bacterium that selectively

Received: 24-10-09.

Accepted: 09-12-09.

Correspondence: Trinidad Parra Cid. Unidad de Investigación. Hospital Universitario de Guadalajara. C/ Donante de Sangre, s/n. 19002 Guadalajara, Spain.e-mail: trpaci@sescam.jccm.es
Calvino-Fernández M, Parra-Cid T. H. pylori and mitochondrial changes in epithelial cells. The role of oxidative stress. Rev Esp Enferm Dig 2010; 102: 41-50.

colonizes the human stomach with a prevalence of up to $90 \%$ in developing populations, and is the second most common pathogen for human beings. In all infectes subjects this bacterium induces chronic gastritis of varying severity, which in around $10-15 \%$ of cases progresses to peptic ulcer (infection is associated with $90 \%$ of gastric and duodenal peptic diseases), and in 1-2\% of subjects ultimately results in MALT lymphoma or gastric adenocarcinoma (1-3) (Fig. 1). Despite this being the most common origin of peptic ulcer and gastric adenocarcinoma, the latter two conditions have different clinical courses and rarely develop concomitantly in the same mucosa.

The mechanisms through which H. pylori damages the gastric mucosa, and which determine the various clinical presentations, are not well understood; whether such mechanisms are exclusively dependant on the characteristics of the organism, the host, or both has not been established. In fact, while obvious toxicity differences are seen between strains $(4,5)$ and $70 \%$ of peptic ulcers exhibit cagA+ organisms $(6,7)$, the percentage of ulcers is lower than estimated according to the high prevalence of this bacterial genotype $(60-80 \%$, depending on populations) (8); on the other hand, despite the high percentage of infected subjects among those who develop gastric carcinoma, a direct mutagenic effect has not been established for these bacteria as yet.

According to theory by Correa et al. (9) three types of bacterium-host interaction exist that may explain gastric mucosal changes:

- The bacterium alters the mucus layer and thus decreases mucin secretion: this renders mucus ineffective 


\section{H. pylori, gatritis and disease}

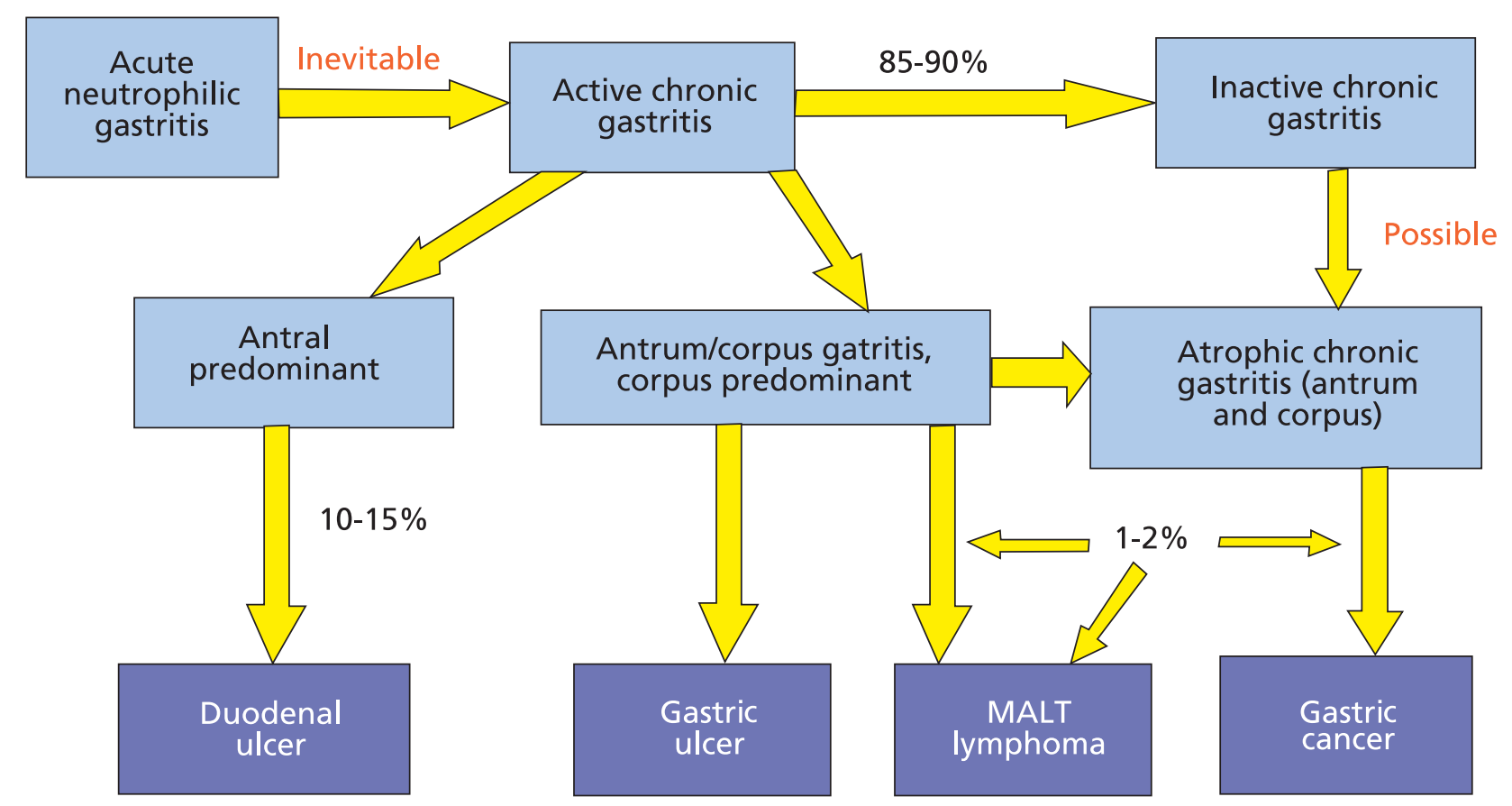

Fig. 1. H. pylori and disease. During infection with H. pylori a number of inflammation patterns are associated with different disease stages.

as a barrier defending the gastric epithelium from acid secretions and luminal toxins. This varies from one subject to the next both according to the infecting strain (cagA+ strains are more toxic) and host characteristics (blood group 0 , non-secretor Lewis antigen, is associated with higher susceptibility to infection and increased risk for gastro-duodenal disease) (10).

-The bacterium causes a migration of inflammatory cells to the gastric mucosa: in some patients this results in nonatrophic, predominantly antral, gastritis associated with the development of duodenal ulcer (11) with no risk for progression to carcinoma (12). However, in other patients this associated gastritis does result in glandular loss, which triggers multifocal atrophic gastritis and intestinal metaplasia (13); these patients exhibit a high risk of progression to gastric carcinoma (14). Determinants and mechanisms involved in the occurrence of such divergent pathways are unknown and represent the primary focus of research.

$-H$. pylori alters cell turnover rates: these bacteria stimulate both cell proliferation (15) and apoptosis (16) in gastric epithelial cells. These changes seem to play a key role in the outcome of infection, including the risk for gastric carcinoma $(17,18)$.

\section{H. PYLORI AND CELL TURNOVER}

Proliferation and apoptosis are essential for turnover in the gastric tissue (19) and rate changes in the latter process seem associated with carcinoma development predisposition, and are considered a risk marker for progression (20).

In the mucosa of infected subjects with gastritis $(17,21)$ or adenocarcinoma (18) increased epithelial proliferation has been found, and while accelerated proliferation is not carcinogenic in itself, highly proliferating cells are more sensitive to mutagenic factors (22), which may represent an association between infection and carcinoma (23).

On the other hand, there is also evidence relating infection to increased apoptosis (24-26). In the non-infected mucosa apoptotic cells are rare (fewer than 3\%) and are situated in superficial areas in gastric glands (17). These cells are found in higher numbers deep in gastric glands in infected tissues, and significantly decrease after eradication.

The apparent conflict entailed by concomitant increases in proliferation and apoptosis may be interpreted from two distinct viewpoints (3): 
- The bacterium induces epithelial cell death, which activates cell proliferation as a mechanism to compensate for cell loss, or

-The bacterium changes the growth rate and causes hyperproliferation, and apoptotic mechanisms are activated to compensate for increased cells.

Evidence is not enough to resolve this circular argument, but the potential fact that $H$. pylori would trigger a change cascade leading to cell self-elimination is most widely endorsed. In this respect, in vitro research has irrefutably proven that infection suffices to significantly increase apoptosis (27-29), hence this is likely the underlying cause of proliferation, thus aimed at restoring homeostatic balance (17).

However, infection chronification with alternating hyperproliferation and apoptosis stages represents a risk factor for balance disruption, either as a result of sustained bacterium-inherent toxicity or because of some cause triggering an exacerbated immune response that ultimately damages epithelial tissues. Thus, excessive apoptosis or proliferation inhibition will result in cell loss, which is observed in gastric ulcers (17). When disbalance occurs towards accelerated epithelial cellular turnover eventual failures in repair mechanisms are propitiated; the mucosa may become infiltrated by fibrotic tissue and/or epithelial replacement by little-differentiated cells may ensue. In fact, glandular tissue atrophy with or without fibrosis is commonplace in association with chronic infection. On the other hand, chronic inflammation and sustained stimulation of epithelial turnover are factors that contribute to the development of intestinal metaplasia. Regulatory mechanisms in these processes are poorly defined, but their significance is highlighted by the association of these morphological changes with sequential progression to gastric carcinoma (9).
In summary, bacterial persistence within the mucosa (either through direct action or because of a subsequent inflammatory response) sequentially induces damage-repair processes that may significantly alter the epithelium (Fig. 2).

\section{H. PYLORI AND APOPTOSIS}

Programmed cell death or apoptosis is an evolutionarily preserved mechanism that uses a complex system for cell self-elimination. It plays a key role in multiple physiological processes (30): immune system and central nervous system functional organization, morphogenetic changes during embryonary development, tissue homeostasis, and clearance of superfluous, ectopic, aging, damaged, mutated, and infected cells (31). In addition, apoptotic processes are involved in the pathogenesis of various disorders including cancer, immune changes, cardiovascular disease, and degenerative conditions (32). Some of these changes are associated with insufficient apoptosis (lymphoma, cancer) whereas others are accompanied by excessive apoptosis (AIDS, amyotrophic lateral sclerosis, ischemia-reperfusion lesions) (33).

This type of cell death is structurally unlike necrosis, and was first described based on characteristic morphology changes. Apoptosis-inducing stimuli may be physiological (lack of growth factors, hormonal environment changes, etc.) or stress-related (UV light, radiation, viral or bacterial infection, etc.), and activate different pathways according to involved molecules and/or organelles, and the morphological and functional changes they induce in cells. Most physiological stimuli initiate apoptosis by activating surface receptors and the so-called extrinsic pathway. In contrast, the origin of stress-induced apoptosis is poorly understood, but mitochondrial in-

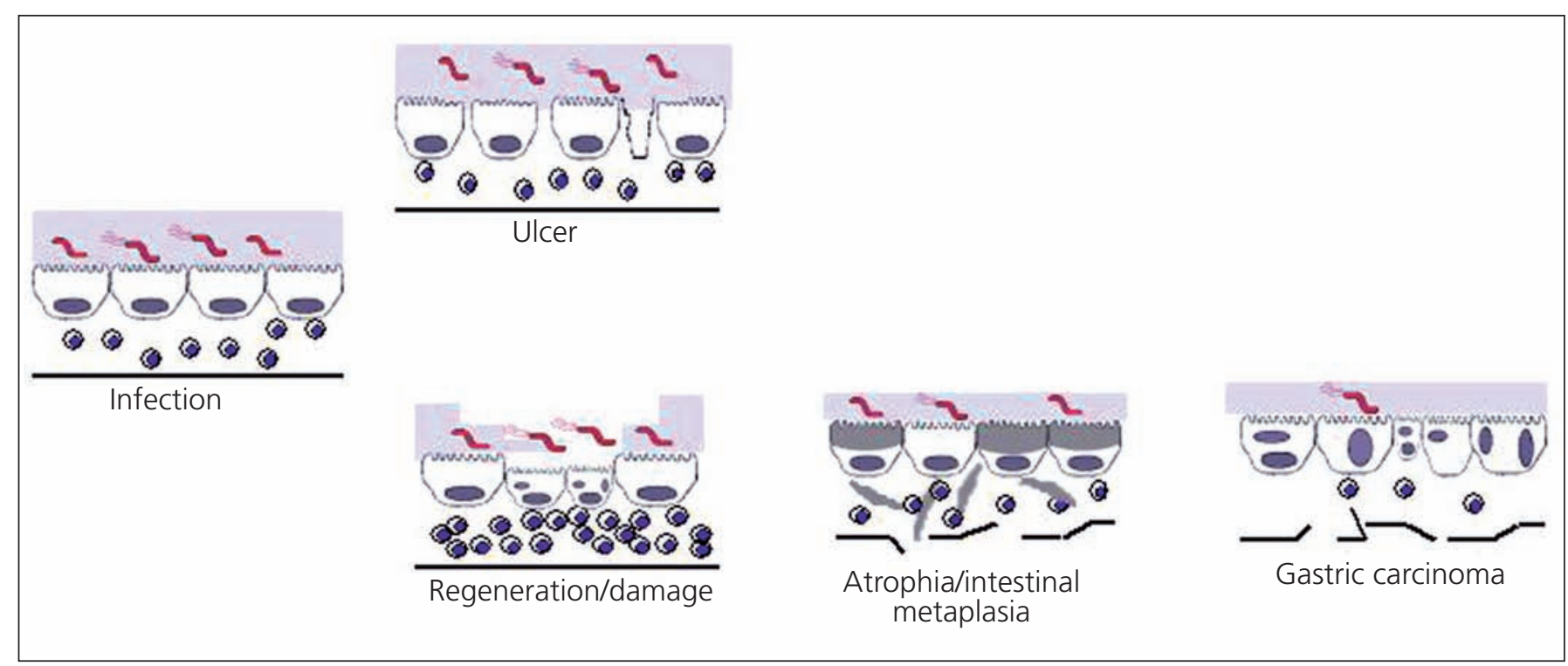

Fig. 2. Mucosal changes following infection with H. pylori. Long-term infection with H. pylori may induce ulceration or repeat "cell damage-repair" cycles, which gradually lead to gastric atrophy, intestinal metaplasia, and ultimately adenocarcinoma. 
volvement early in the intracellular signaling cascade making up the intrinsic pathway is now established (35).

\section{Apoptosis mechanisms}

- "Extrinsic or death receptor pathway": following an activation of "death receptors" (molecules in the TNF receptor superfamily, including TNF-R1, CD95 (Fas) and TRAIL-R1 and -R2), caspase-8 is activated after being recruited into the DISC complex through FADD (Fas-associated death domain) (36) (Fig. 3). The cascade then activates caspase- 3 and eventually induces apoptosis (37).

A number of reported studies implicate death receptors in $H$. pylori-induced apoptosis $(16,38,39)$, as strains or coculture supernatants induce Fas/FasL overexpression in epithelial cells. However, whether these receptors represent the primary apoptosis route as induced by these bacteria remains unknown.

- "Intrinsic or mitochondrial pathway": various signals may converge at the mitochondrial level to induce a translocation of mitochondrial cytochrome $c$ (cyt $c$ ) into the cytosol. The binding of cyt $c$ to the Apaf-1 (Apoptosis protease-activating factor-1) complex recruits procaspase-9, which following hydrolization to caspase-9 activates procaspase-3 (40) (Fig. 3). Proteins in the Bcl-2 (B- cell leukemia/lymphoma 2) family represent the primary regulators in this pathway: antiapoptotic members (Bcl-2, Bcl- $\mathrm{X}_{\mathrm{L}}, \mathrm{Bcl}-\mathrm{W}, \mathrm{Bfl}-1$ and Mcl-1) act as inhibitors while proapoptotic members (Bax, Bak, Bad, Bcl- $\mathrm{X}_{\mathrm{s}}$, Bid, Bik, Bim and Hrk) serve as promoters $(41,42)$ by blocking or enhancing, respectively, the release of cyt $c$ into the cytosol.

While the origin and evolution of the extrinsic and intrinsic pathways differ, both apoptotic cascades converge at caspase-3; after caspasa's activation, the changes experienced by cells are identical regardless of the initial pathway (Fig. 3).

Therefore, following exposure to stress-related stimuli, cells enter a highly regulated, controlled process leading to self-elimination. In this process biochemical and morphological changes occur, that involve all cellular compartments and include cellular and nuclear contraction, translocation of phosphatidilserine on the outer leaflet of the lipid bilayer, caspase activation, membrane "blebbing", chromatine condensation, apoptotic bodies formation, DNA fragmentation (43), and specifically when apoptosis results from the intrinsic pathway, various mitochondrial changes (Fig. 3).

Mitochondrial changes during infection with $H$.pylori have been scarcely researched even when some intrinsic pathway components have been known to be activated by

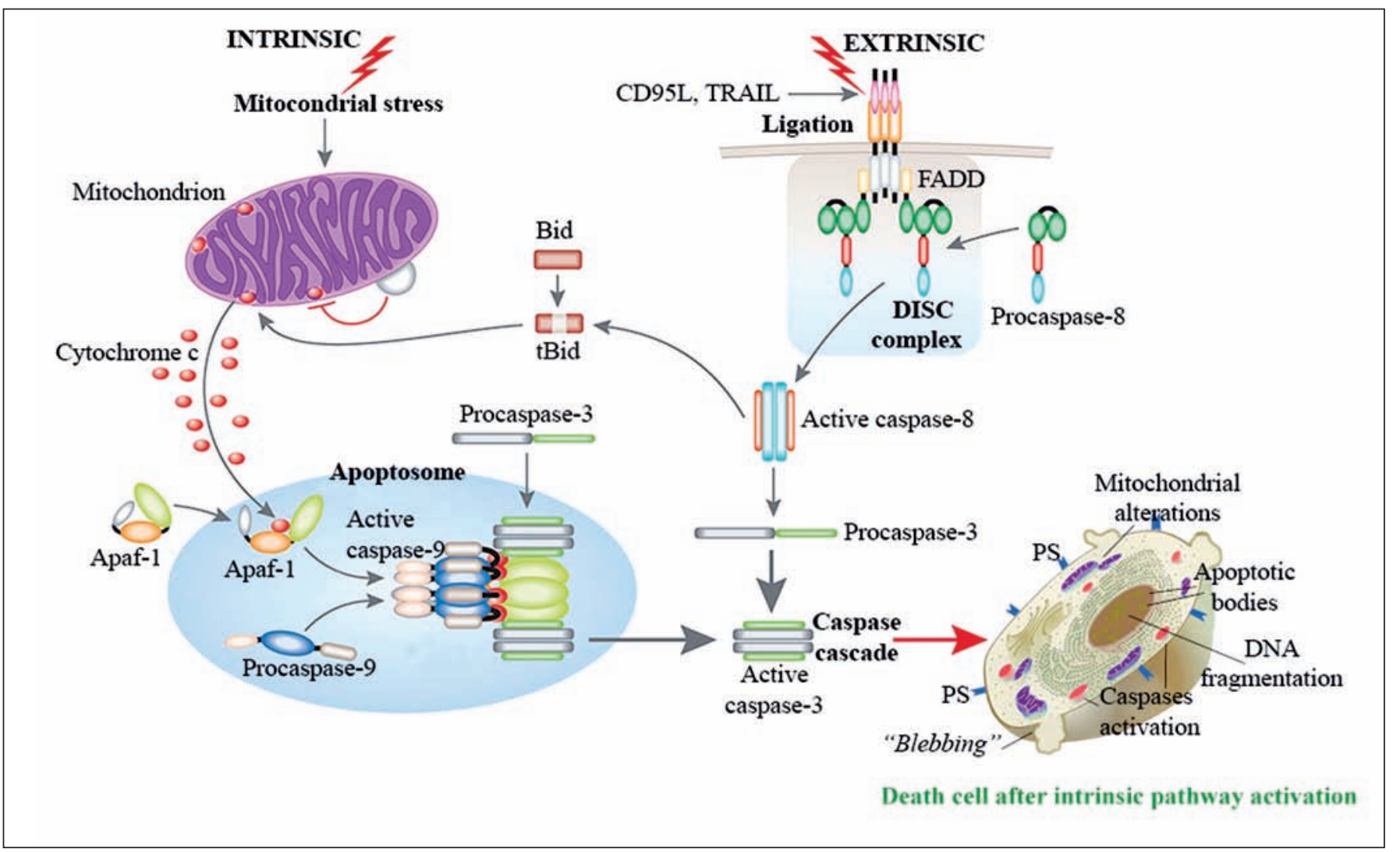

Fig. 3. Apoptotic pathways: the extrinsic pathway involves so-called death receptors (CD95, TRAIL); the intrinsic one involves mitochondrial granules. Both pathways converge at caspase-3 activation, where classic biochemical and morphological changes in association with the apoptotic phenotype are originated. 
this bacterium for years. Thus, some authors point out an association with Bcl-2 family members (44-46), and the organism has been shown to increase the expression of proapoptotic protein Bax in the gastric mucosa. Zhang et al. (47) demonstrated in a gastric adenocarcinoma cell line cultivated with $H$. pylori that, in parallel with apoptosis induction, there was an increase in bax, bid and bcl2 expression, as well as caspase 3 and 9 activation; they established a relationship between both facts by using caspase inhibitors, which decreased apoptosis. The involvement of the Bcl-2 family suggests that the mitochondrial pathway also plays a role in apoptosis as induced by $H$. pylori. Along this same line Kim et al. recently reported data pointing to bacterial protein gamma-glutamyltranspeptidase as an activator of this pathway (48).

\section{H.PYLORI AND APOPTOSIS-RELATED MITOCHONDRIAL CHANGES}

While stimuli capable of triggering cell death through apoptosis are many, the changes they induce all converge at mitochondria. The role of this organelle as an apoptosis regulator (49) specifically consists of proteins release from the intermembrane space into the cytosol, which requires a number of functionality-conditioning morphological changes.

The most relevant mitochondrial function in eukaryotic cells is energy production in the form of ATP molecules from oxygen and metabolic by products derived from beta-fatty acid oxidation, urea cycle, and respiratory chain (50). Their structure and compartmentalization are highly related to a perfect performance of these functions. Every mitochondrion has a double lipid envelope
(Fig. 4A) delimiting the matrix, located within the inner mitochondrial membrane (IMM), and the intermembrane space, located between the IMM and the outer mitochondrial membrane (OMM). IMM cristae or invaginations increase the area where specific mitochondrial processes develop (electron transport and oxidative phosphorylation) (Fig. 4B). The efficacy of these processes greatly depends on the bilayer's appropriate composition and structure, which relies on the role of the phospholipid cardiolipin. CL is a specific component of IMM and the most abundant at that; protein complexes (complexes IIV) in the respiratory chain that carry e- from NAD $(\mathrm{P}) \mathrm{H}$ and $\mathrm{FADH}_{2}$ molecules to oxygen molecules to result in reduction to $\mathrm{H}_{2} \mathrm{O}$ (Fig. 4B) are anchored on CL.

In addition to these complexes other proteins are embedded on the IMM, with cyt $c$ being most significant amongst them. For years, e-transportation from complex III to complex IV in the respiratory chain was deemed to be their only function, until 1996 that Wang et al. (51) revealed their role in apoptotic processes after the addition of dATP to normal-growth cells to induce apoptosis, their presence was detected in the cytosol. Various data have since corroborated their rapid release into the cytosol $(52,53)$ following some apoptotic stimuli.

Particularly relevant is the electrostatic bond between CL and cyt $c$ in the IMM (54) (Fig. 4B) as this implies the phospholipid is involved in processes where cyt $c$ translocation to the cytosol is unnecessary (51). The oxidation of CL by free radicals (55) has been shown to alter such bond, to substantially modify IMM structure, and eventually to induce malfunctioning in the electron transport chain, which translates into decreased transmembrane potential.

Once in the intermembrane space cyt $c$ must cross the OMM to enter the cytosol. Petit et al. (56) explain this

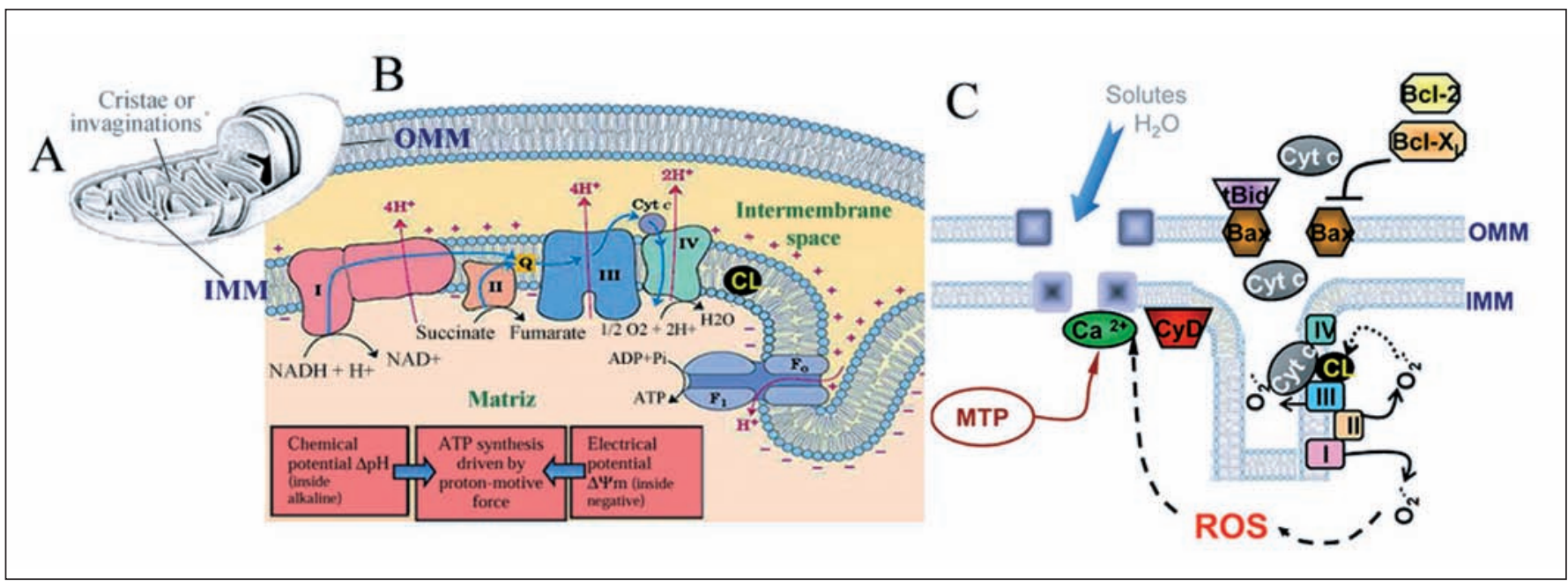

Fig. 4. Mitochondria: structure and function. A. Mitochondrial structure. B. Mitochondrial membranes: relationship between electron transport chain complexes, cytochrome c, and the phospholipid cardiolipin where they are inserted. C. Mitochondrial transition pore formation: ruptured links between protein complexes and cardiolipin, and passage of cytochrome c into the cytosol (78). OMM: external mitochondrial membrane; IMM: inner mitochondrial membrane; CL: cardiolipin; cit c: cytochrome c; MTP: mitochondrial transition pores. 
stage by means of mitochondrial transition pores (MTPs) (Fig. 4C). These pore result from the opening of a conductance channel in the IMM because of electrochemical gradient dissipation and osmotic swelling arising from high salt contents in the matrix, which ultimately breaks the OMM. A second model supports the presence of a specific channel $(57,58)$ in which Bax, Bid and CL play a role. Bax is present in free monomeric form in the cytosol or weakly bound to the OMM until its binding of Bid, which determines a complete insertion into the membrane where at least 4 tetrameres result, which causes permeabilization. Bid action on Bax is regulated by the rest of molecules in the Bcl-2 family: antiapoptotic molecules Bcl-2 and $\mathrm{Bcl}-\mathrm{X}_{\mathrm{L}}$ inhibit this whereas proapoptotic $\mathrm{Bad}$ and Bik inhibit the antiapoptotic molecules function. $\mathrm{CL}$ is therefore insufficient but necessary for OMM permeabilization. Another possibility, which is consistent with the above, is that Bax when inserted in the mitochondrion physically and functionally interacts with some protein in the MTP complex, this being the ultimate cause of permeabilization.

Whatever the route taken by cyt $c$ to translocate into the cytosol, a caspase activation cascade is initiated that represents the point of no return in the pathway to cell elimination.

\section{H. PYLORI AND ROS}

There is scientific evidence that reactive oxygen species (ROS) play a relevant role in the pathogenesis of inflammation in the gastroduodenal mucosa, peptic ulcer disease, and - likely - gastric cancer (59). While an association has also been established between H. pylori infection and exacerbated free radical synthesis $(60,61)$, many clinical data suggest that other factors inherent to host conditions (stress, diet, tobacco, hygiene, genetics...) contribute to the pathogenesis of this infection (62). It should be noted that some of these factors, including ingested food and tobacco smoke (63), directly influence mucosal oxidative status, as they expose the gastric epithelium to the ROS they generate within the gastric lumen in a sustained manner.

Besides these ROS other potential sources associated with infection include:

1. Inflammatory cells (neutrophils, macrophages) infiltrating the mucosa (64).

2. Gastric epithelial cells (61).

3 . The bacterium itself, which generates a great amount of superoxide anion $\left(\mathrm{O}_{2}{ }^{-}\right)$to inhibit the bactericidal effects of nitric oxide as synthesized by inflammatory cells (65).

Zhang et al. (66) demonstrated that increased ROS in the mucosa of subjects with $H$.pylori-associated gastritis can be correlated with bacterial load.

From a physiological standpoint cells protect themselves from oxidative stress by activating antioxidant defense mechanisms involving oxygen scavenger enzymes such as superoxide dismutase, catalase and glutathione peroxidase (67), as well as vitamins (Vit) E and $\mathrm{C}$.

The mechanisms by which H. pylori products (and the ensuing inflammation) affect the ability of gastric cells to protect themselves from ROS are unknown (63). H. pylori is known to release catalase and superoxide dismutase but in amounts likely insufficient to clear excess extracellular oxidants (67), as these enzymes primarily play a role in the elimination of ROS generated by the bacterium itself. Furthermore, in subjects with predominantly antral infection Vit E levels are known to decrease in the gastric body, which may reflect a mobilization of antioxidant defense mechanisms to maximally inflamed sites (68). On the other hand, infected subjects have significantly lower Vit E and Vit C levels (69).

In short, antioxidant systems seem also involved in infection to counteract increased ROS (61), hence their impairment or deficiency would notably reduce the ability of cells to tolerate an environment rich in free radicals. A study in rats with aspirin-induced gastric lesions showed that Vit E deficiency facilitates peptic ulcer, and that Vit E supplementation has protective actions, possibly because of its capacity to limit lipid peroxidation brought about by acetylsalicylic acid (70). Another study in Mongolian gerbils concludes that Vit $\mathrm{C}$ or Vit $\mathrm{E}$ supplementation protects from $H$. pylori-induced gastritis in the short term, its effects seemingly declining during persistent infection (71). Experiments in rats with other antioxidants, including a sunflower oil compound (72) and a flavonoid derivative (73), have shown an absence of gastric mucosal damage following exposure to indomethacin or ethanol, respectively.

Thus, when excessive ROS generated by bacteria on the epithelium is augmented by reduce antioxidant defense effectiveness, the risk of toxicity from oxidation and DNA damage is potentially increased (63). An impaired "oxidant-antioxidant" balance may then result in cell death, which would alter cell proliferation rate and/or facilitate the development of mutations leading to increased oncogene expression, hence the association between infection and gastric cancer (74).

\section{H. PYLORI, APOPTOSIS, INTRINSIC PATHWAY, ROS, AND ANTIOXIDANTS}

As seen above, the intrinsic pathway has been recently involved in the development of apoptosis in the H.pylori-infected gastric mucosa (47). The relationship between apoptosis during infection and increased oxidative stress is also well known $(75,76)$, but no data associate bacteria with free radicals and apoptosis through the mitochondrial pathway. 
Our team has studied bacteria-induced changes in mitochondria (27) using the AGS gastric epithelial cell line to demonstrate that bacteria activate intrinsic pathway apoptosis. Furthermore, these same experiments performed in cells previously supplemented with Vit E show the indisputable involvement of ROS in these changes. Our results allow to develop a hypothesis suggesting the mechanisms for these changes (Fig. 5):

To demonstrate oxidative stress we assessed the synthesis of free radicals and the status of antioxidant defenses both at cell and mitochondrial level. We measured "reactive oxygen species" (ROS) and superoxide anion levels (1a), the latter being the primary, specific mitochondrial free radical. In parallel to these molecules' induction we saw an impairment of antioxidant defenses in terms of reduced glutathione (GSH) and NADPH contents (1b). GSH contents is a reflection of the highest physiological antioxidant reserve whereas NADPH reflects electron transport chain functionality, which is impaired by oxidative processes.

Once an impaired oxidant/antioxidant balance was demonstrated we studied whether oxidative stress also affected mitochondria by oxidating mitochondrial components. To this end, given that lipids are the most suscepti- ble molecules to oxidation, we analyzed CL (2), the primary phospholipidic constituent of the IMM. Its obvious oxidation led us to consider that cardiolipin degradation (3) must affect the electron transport chain (4), whose components are inserted in CL, which in turn must result in low function and consequently in membrane potential loss (5).

CL oxidation and membrane potential loss are theoretically associated with increased mitochondrial membrane permeability as a result of MTP opening (6) by any of the above mechanisms, which will facilitate substance exchange between mitochondria and cytosol. In our experiments we detected that MTPs were indeed opened, and that cyt c levels increased in the cytosol as a result of its release from mitochondria (7). The release of cyt $c$ into the cytosol is also related to changes in family $\mathrm{Bcl}-2$ component levels (8), with balance shifting towards proapoptotic members. We detected an increased expression of proapoptotic genes (bax and bid) concomitant with a decreased expression of the antiapoptotic gene bcl-2, which had already been found in previous experiments by other research teams $(44,47,77)$. Cytosolic cyt c activates the caspase cascade (9), which showed in our experiments; both the initiating caspase 2 and effector caspases 6 (spe-

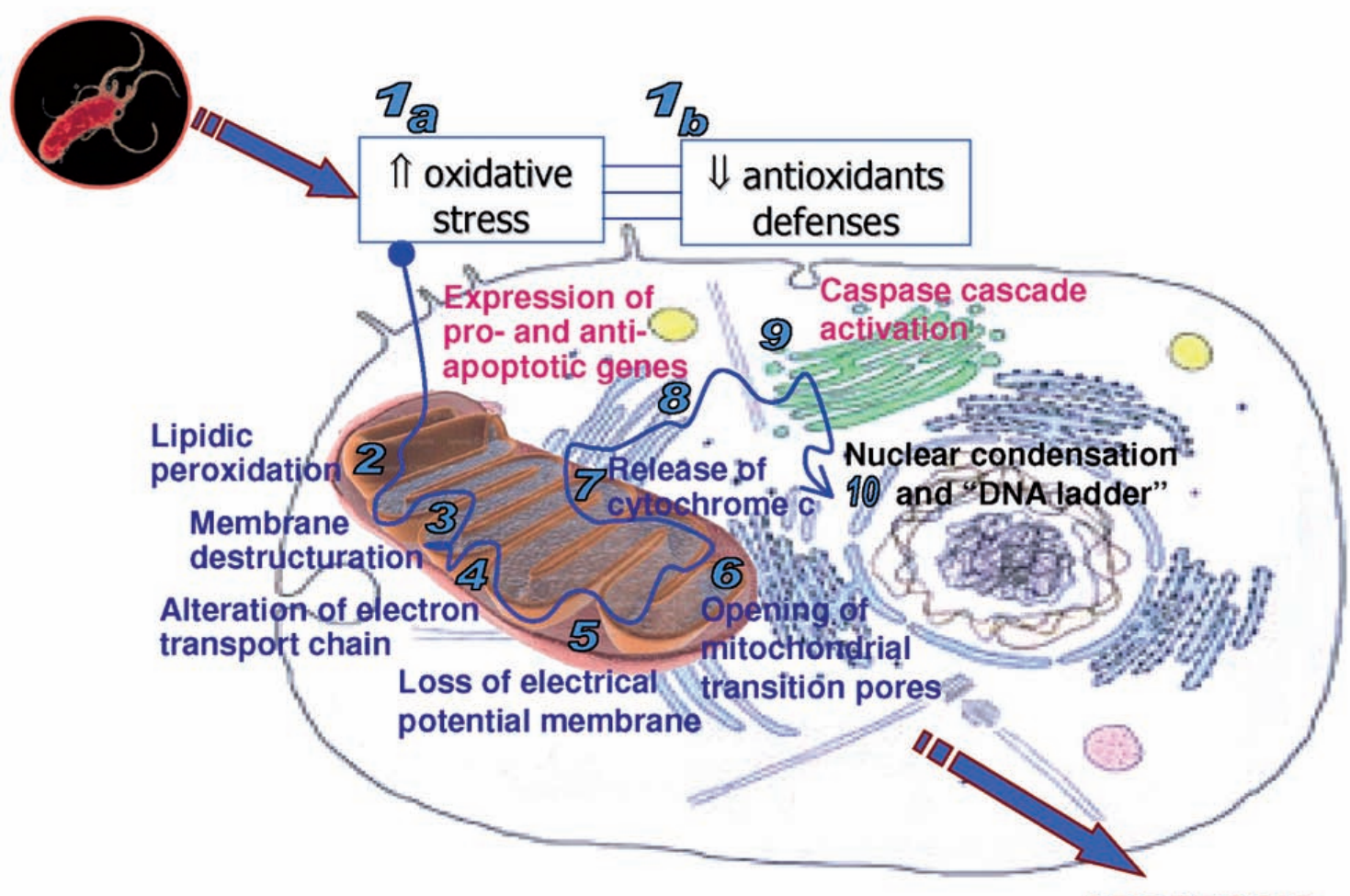

APOPTOSIS

Fig. 5. A theoretical model of H. pylori toxicity on gastric mucosal cells. Oxidative stress as induced by $\mathrm{H}$. pylori initiates a change cascade that leads gastric cells to apoptotic death by mitochondrial pathway. 
cific to the mitochondrial apoptotic pathway) and 3 (molecule where the intrinsic and extrinsic pathways converge) were overexpressed.

For the cell to initiate apoptosis all these mitochondrial and cytosolic changes must translate in the nucleus into chromatin condensation, apoptotic body development, and DNA fragmentation (10), facts that we showed in our cells by visualizing nuclei with specific markers and identifying typical "DNA ladder" patterns in agarose gel.

If oxidative stress is at the origin of all these changes, therapy with antioxidants would prevent them as well as their ultimate consequence: apoptosis. In our experiments the addition of Vit $\mathrm{E}$ at $10^{-4} \mathrm{M}$ concentration restored oxidative status and prevented or reduced all these alterations, with a statistically significant decrease of apoptosis in our cultures.

Experiments were performed using confocal microscopy, flow cytometry, Western blot, real-time PCR, and ELISA. Mitochondrial structure and function analyses were carried out with the following specific markers:

- MitoSOX Red to establish mitochondrial $\mathrm{O}_{2}$ contents.

- JC-1 and MitoTrackers (Orange and Green) to analyze membrane potential.

- Calcein-AM and $\mathrm{CoCl}_{2}$ to determine MTP aperture.

$-10-\mathrm{N}$-nonyl acridine orange to assess cardiolipin oxidation.

\section{CONCLUSIONS}

Based on these results and on evidences reported before our data were published, we show the likely beneficial effect of therapy with antioxidants in patients with $H$. pylori infection. Antioxidants would reduce the impact of exacerbated oxidative stress on the mucosa, and block the ensuing damage-regeneration processes that seem to arise with long-term infection, thus allowing to prevent progression to severe diseases such as ulcer or carcinoma.

Furthermore, we suggest this would be a highly useful preventive method for societies where eradicating therapy is less common and indiscriminate when compared to ours.

\section{ACKNOWLEDGEMENTS}

This review was partly funded by research grant GC02025 of Fundación para la Investigación Sanitaria en Castilla La-Mancha (FISCAM). The work of M. Calvino was funded by Instituto de Salud Carlos III through a "Contrato de Apoyo a la Investigación en el SNS" (CA07/00157).

\section{REFERENCES}

1. Moss S, Calam J. Helicobacter pylori and peptic ulcers: the present position. Gut 1992; 33: 289-92.

2. Parsonnet J, Friedman GD, Vandersteen DP, Chang Y, Vogelman $\mathrm{JH}$, Orentreich N, et al. Helicobacter pylori infection and the risk of gastric carcinoma. N Engl J Med 1991; 325: 1127-31.

3. Ernst PB, Gold BD. The disease spectrum of Helicobacter pylori: the immunopathogenesis of gastroduodenal ulcer and gastric cancer. Annu Rev Microbiol 2000; 54: 615-40.

4. Blaser MJ, Perez-Perez GI, Kleanthous H, Cover TL, Peek RM, Chyou $\mathrm{PH}$, et al. Infection with Helicobacter pylori strains possessing cagA is associated with an increased risk of developing adenocarcinoma of the stomach. Cancer Res 1995; 55: 2111-5.

5. Crabtree JE, Farmery SM. Helicobacter pylori and gastric mucosal cytokines: evidence that CagA-positive strains are more virulent. Lab Invest 1995; 73: 742-5.

6. Aydin F, Kaklikkaya N, Ozgur O, Cubukcu K, Kilic AO, Tosun I, et al. Distribution of vacA alleles and cagA status of Helicobacter pylori in peptic ulcer disease and non-ulcer dyspepsia. Clin Microbiol Infect 2004; 10: 1102-4

7. van Doorn LJ, Figueiredo C, Sanna R, Plaisier A, Schneeberger P, de Boer W, et al. Clinical relevance of the cagA, vacA, and iceA status of Helicobacter pylori. Gastroenterology 1998; 115: 58-66.

8. Yamaoka Y, Kato M, Asaka M. Geographic differences in gastric cancer incidence can be explained by differences between Helicobacter pylori strains. Intern Med 2008; 47: 1077-83.

9. Correa P, Miller MJ. Carcinogenesis, apoptosis and cell proliferation. Br Med Bull 1998; 54: 151-62.

10. Wirth HP, Yang M, Karita M, Blaser MJ. Expression of the human cell surface glycoconjugates Lewis $\mathrm{x}$ and Lewis y by Helicobacter pylori isolates is related to cagA status. Infect Immun 1996; 64: 4598-605.

11. Dixon MF, Genta RM, Yardley JH, Correa P. Classification and grading of gastritis. The updated Sydney System. International Workshop on the Histopathology of Gastritis, Houston 1994. Am J Surg Pathol 1996; 20: 1161-81.

12. Hansson LE, Nyren O, Hsing AW, Bergstrom R, Josefsson S, Chow $\mathrm{WH}$, et al. The risk of stomach cancer in patients with gastric or duodenal ulcer disease. N Engl J Med 1996; 335: 242-9.

13. Fontham ET, Ruiz B, Perez A, Hunter F, Correa P. Determinants of Helicobacter pylori infection and chronic gastritis. Am J Gastroenterol 1995; 90: 1094-101.

14. Filipe MI, Munoz N, Matko I, Kato I, Pompe-Kirn V, Jutersek A, et al. Intestinal metaplasia types and the risk of gastric cancer: a cohort study in Slovenia. Int J Cancer 1994; 57: 324-9.

15. Fan XG, Kelleher D, Fan XJ, Xia HX, Keeling PW. Helicobacter pylori increases proliferation of gastric epithelial cells. Gut 1996; 38: 19-22.

16. Jones NL, Day AS, Jennings HA, Sherman PM. Helicobacter pylori induces gastric epithelial cell apoptosis in association with increased Fas receptor expression. Infect Immun 1999; 67: 4237-42.

17. Jang TJ, Kim JR. Proliferation and apoptosis in gastric antral epithelial cells of patients infected with Helicobacter pylori. J Gastroenterol 2000; 35: 265-71.

18. Yabuki N, Sasano H, Tobita M, Imatani A, Hoshi T, Kato K, et al. Analysis of cell damage and proliferation in Helicobacter pylori-infected human gastric mucosa from patients with gastric adenocarcinoma. Am J Pathol 1997; 151: 821-9.

19. Hall PA, Coates PJ, Ansari B, Hopwood D. Regulation of cell number in the mammalian gastrointestinal tract: the importance of apoptosis. J Cell Sci 1994; 107 (Pt 12): 3569-77.

20. Fearon ER, Vogelstein B. A genetic model for colorectal tumorigenesis. Cell 1990; 61: 759-67.

21. Correa P RB, Shi TY, Janney A, Sobhan M, Torrado J, Hunter F. Helicobacter pylori and nucleolar organizer regions in the gastric antral mucosa. Am J Clin Pathol 1994; 101: 656-60.

22. Ames BN, Gold LS. Too many rodent carcinogens: mitogenesis increases mutagenesis. Science 1990; 249: 970-1.

23. Zhang ZW, Farthing MJ. Molecular mechanisms of H. pylori associated gastric carcinogenesis. World J Gastroenterol 1999; 5: 36974. 
24. Moss SF, Calam J, Agarwal B, Wang S, Holt PR. Induction of gastric epithelial apoptosis by Helicobacter pylori. Gut 1996; 38: 498-501.

25. Jones NL, Shannon PT, Cutz E, Yeger H, Sherman PM. Increase in proliferation and apoptosis of gastric epithelial cells early in the natural history of Helicobacter pylori infection. Am J Pathol 1997; 151: 1695-703.

26. Shibayama K, Doi Y, Shibata N, Yagi T, Nada T, Inuma Y, et al Apoptotic signaling pathway activated by Helicobacter pylori infection and increase of apoptosis-inducing activity under serum-starved conditions. Infect Immun 2001; 69: 3181-9.

27. Calvino-Fernandez M, Benito-Martinez S, Parra-Cid T. Oxidative stress by Helicobacter pylori causes apoptosis through mitochondrial pathway in gastric epithelial cells. Apoptosis 2008; 13: 1267-80.

28. Ding SZ, Smith MF, Jr., Goldberg JB. Helicobacter pylori and mitogen-activated protein kinases regulate the cell cycle, proliferation and apoptosis in gastric epithelial cells. J Gastroenterol Hepatol 2008; 23: 67-78.

29. Wei J, O'Brien D, Vilgelm A, Piazuelo MB, Correa P, Washington MK, et al. Interaction of Helicobacter pylori with gastric epithelial cells is mediated by the p53 protein family. Gastroenterology 2008; 134: $1412-23$

30. Kerr JF, Wyllie AH, Currie AR. Apoptosis: a basic biological phenomenon with wide-ranging implications in tissue kinetics. Br J Cancer 1972; 26: 239-57.

31. Gulbins E, Dreschers S, Bock J. Role of mitochondria in apoptosis. Exp Physiol 2003; 88: 85-90.

32. Thompson CB. Apoptosis in the pathogenesis and treatment of disease. Science 1995; 267: 1456-62.

33. Elmore S. Apoptosis: a review of programmed cell death. Toxicol Pathol 2007; 35: 495-516.

34. Schultz DR, Harrington WJ, Jr. Apoptosis: programmed cell death at a molecular level. Semin Arthritis Rheum 2003; 32: 345-69.

35. Ferri KF, Kroemer G. Organelle-specific initiation of cell death pathways. Nat Cell Biol 2001; 3: E255-63.

36. MacFarlane M, Williams AC. Apoptosis and disease: a life or death decision. EMBO Rep 2004; 5: 674-8.

37. Kuwano K, Hara N. Signal transduction pathways of apoptosis and inflammation induced by the tumor necrosis factor receptor family. Am J Respir Cell Mol Biol 2000; 22: 147-9.

38. Domhan S, Stremmel W, Rudi J. Role of apoptosis and CD95-receptor/ligand system in aspirin- and Helicobacter pylori-induced cell death. Eur J Clin Invest 2004; 34: 422-8.

39. Houghton J, Korah RM, Condon MR, Kim KH. Apoptosis in Helicobacter pylori-associated gastric and duodenal ulcer disease is mediated via the Fas antigen pathway. Dig Dis Sci 1999; 44: 465-78.

40. Jeong SY, Seol DW. The role of mitochondria in apoptosis. BMB Rep 2008; 41: 11-22.

41. Harris $\mathrm{MH}$, Thompson $\mathrm{CB}$. The role of the Bcl-2 family in the regulation of outer mitochondrial membrane permeability. Cell Death Differ 2000; 7: 1182-91.

42. Kuwana T, Bouchier-Hayes L, Chipuk JE, Bonzon C, Sullivan BA, Green DR, et al. BH3 domains of BH3-only proteins differentially regulate Bax-mediated mitochondrial membrane permeabilization both directly and indirectly. Mol Cell 2005; 17: 525-35.

43. Saraste A, Pulkki K. Morphologic and biochemical hallmarks of apoptosis. Cardiovasc Res 2000; 45: 528-37.

44. Ashktorab H, Frank S, Khaled AR, Durum SK, Kifle B, Smoot DT Bax translocation and mitochondrial fragmentation induced by Helicobacter pylori. Gut 2004; 53: 805-13.

45. Yamasaki E, Wada A, Kumatori A, Nakagawa I, Funao J, Nakayama $\mathrm{M}$, et al. Helicobacter pylori vacuolating cytotoxin induces activation of the proapoptotic proteins Bax and Bak, leading to cytochrome c release and cell death, independent of vacuolation. J Biol Chem 2006; 281: 11250-9.

46. Liu HF, Liu WW, Wang GA, Teng XC. Effect of Helicobacter pylori infection on Bax protein expression in patients with gastric precancerous lesions. World J Gastroenterol 2005; 11: 5899-901.

47. Zhang H, Fang DC, Lan CH, Luo YH. Helicobacter pylori infection induces apoptosis in gastric cancer cells through the mitochondrial pathway. J Gastroenterol Hepatol 2007; 22: 1051-6.

48. Kim KM, Lee SG, Park MG, Song JY, Kang HL, Lee WK, et al. Gamma-glutamyltranspeptidase of Helicobacter pylori induces mitochondria-mediated apoptosis in AGS cells. Biochem Biophys Res
Commun 2007; 355: 562-7.

49. Orrenius S. Mitochondrial regulation of apoptotic cell death. Toxicol Lett 2004; 149: 19-23.

50. Chinnery PF, Schon EA. Mitochondria. J Neurol Neurosurg Psychiatry 2003; 74: 1188-99.

51. Liu X, Kim CN, Yang J, Jemmerson R, Wang X. Induction of apoptotic program in cell-free extracts: requirement for dATP and cytochrome c. Cell 1996; 86: 147-57.

52. Yang J, Liu X, Bhalla K, Kim CN, Ibrado AM, Cai J, et al. Prevention of apoptosis by Bcl-2: release of cytochrome $\mathrm{c}$ from mitochondria blocked. Science 1997; 275: 1129-32.

53. Kluck RM, Bossy-Wetzel E, Green DR, Newmeyer DD. The release of cytochrome $\mathrm{c}$ from mitochondria: a primary site for Bcl-2 regulation of apoptosis. Science 1997; 275: 1132-6.

54. Iverson SL, Orrenius S. The cardiolipin-cytochrome $\mathrm{c}$ interaction and the mitochondrial regulation of apoptosis. Arch Biochem Biophys 2004; 423: 37-46.

55. Petrosillo G, Ruggiero FM, Paradies G. Role of reactive oxygen species and cardiolipin in the release of cytochrome c from mitochondria. FASEB J 2003; 17: 2202-8.

56. Petit PX, Susin SA, Zamzami N, Mignotte B, Kroemer G. Mitochondria and programmed cell death: back to the future. FEBS Lett 1996; 396: 7-13.

57. Kuwana T, Mackey MR, Perkins G, Ellisman MH, Latterich M, Schneiter R, et al. Bid, Bax, and lipids cooperate to form supramolecular openings in the outer mitochondrial membrane. Cell 2002; 111: $331-42$.

58. Zamzami N, Kroemer G. Apoptosis: mitochondrial membrane permeabilization--the (w)hole story? Curr Biol 2003; 13: R71-3.

59. Phull PS, Green CJ, Jacyna MR. A radical view of the stomach: the role of oxygen-derived free radicals and anti-oxidants in gastroduodenal disease. Eur J Gastroenterol Hepatol 1995; 7: 265-74.

60. Davies GR, Simmonds NJ, Stevens TR, Sheaff MT, Banatvala N, Laurenson IF, et al. Helicobacter pylori stimulates antral mucosal reactive oxygen metabolite production in vivo. Gut 1994; 35: 179-85.

61. Bagchi D, Bhattacharya G, Stohs SJ. Production of reactive oxygen species by gastric cells in association with Helicobacter pylori. Free Radic Res 1996; 24: 439-50.

62. Oh TY, Yeo M, Han SU, Cho YK, Kim YB, Chung MH, et al. Synergism of Helicobacter pylori infection and stress on the augmentation of gastric mucosal damage and its prevention with alpha-tocopherol. Free Radic Biol Med 2005; 38: 1447-57.

63. Smoot DT, Elliott TB, Verspaget HW, Jones D, Allen CR, Vernon $\mathrm{KG}$, et al. Influence of Helicobacter pylori on reactive oxygen-induced gastric epithelial cell injury. Carcinogenesis 2000; 21: 2091-5.

64. Augusto AC, Miguel F, Mendonca S, Pedrazzoli J, Jr., Gurgueira SA. Oxidative stress expression status associated to Helicobacter pylori virulence in gastric diseases. Clin Biochem 2007; 40: 615-22.

65. Nagata K, Yu H, Nishikawa M, Kashiba M, Nakamura A, Sato EF, et al. Helicobacter pylori generates superoxide radicals and modulates nitric oxide metabolism. J Biol Chem 1998; 273: 14071-3.

66. Zhang Q, Dawodu JB, Etolhi G, Husain A, Gemmell CG, Russell RI. Relationship between the mucosal production of reactive oxygen radicals and density of Helicobacter pylori in patients with duodenal ulcer. Eur J Gastroenterol Hepatol 1997; 9: 261-5.

67. Mori M, Suzuki H, Suzuki M, Kai A, Miura S, Ishii H. Catalase and superoxide dismutase secreted from Helicobacter pylori. Helicobacter 1997; 2: 100-5

68. Phull PS, Price AB, Thorniley MS, Green CJ, Jacyna MR. Vitamin E concentrations in the human stomach and duodenum--correlation with Helicobacter pylori infection. Gut 1996; 39: 31-5.

69. Annibale B, Capurso G, Delle Fave G. Consequences of Helicobacter pylori infection on the absorption of micronutrients. Dig Liver Dis 2002; 34(Supl. 2): S72-7.

70. Jaarin K, Gapor MT, Nafeeza MI, Fauzee AM. Effect of various doses of palm vitamin $\mathrm{E}$ and tocopherol on aspirin-induced gastric lesions in rats. Int J Exp Pathol 2002; 83: 295-302.

71. Sun YQ, Girgensone I, Leanderson P, Petersson F, Borch K. Effects of antioxidant vitamin supplements on Helicobacter pylori-induced gastritis in Mongolian gerbils. Helicobacter 2005; 10: 33-42.

72. Zamora Z, Gonzalez R, Guanche D, Merino N, Menendez S, Hernandez F, et al. Ozonized sunflower oil reduces oxidative damage in- 
duced by indomethacin in rat gastric mucosa. Inflamm Res 2008; 57 : 39-43.

73. Liu JL, Du J, Fan LL, Liu XY, Gu L, Ge YB. Effects of quercetin on hyper-proliferation of gastric mucosal cells in rats treated with chronic oral ethanol through the reactive oxygen species-nitric oxide pathway. World J Gastroenterol 2008; 14: 3242-8.

74. Obst B, Wagner S, Sewing KF, Beil W. Helicobacter pylori causes DNA damage in gastric epithelial cells. Carcinogenesis 2000; 21: 1111-5.

75. Ding SZ, Minohara Y, Fan XJ, Wang J, Reyes VE, Patel J, et al. Helicobacter pylori infection induces oxidative stress and programmed cell death in human gastric epithelial cells. Infect Immun 2007; 75: 4030-9.

76. Olivares D, Gisbert JP, Pajares JM. Helicobacter pylori infection and gastric mucosal epithelial cell apoptosis. Rev Esp Enferm Dig 2005; 97: 505-20.

77. Chu SH, Lim JW, Kim KH, Kim H. NF-kappaB and Bcl-2 in Helicobacter pylori-induced apoptosis in gastric epithelial cells. Ann N Y Acad Sci 2003; 1010: 568-72.

78. Gogvadze V, Zhivotovsky B. Alteration of mitochondrial function and cell sensitization to death. J Bioenerg Biomembr 2007; 39: 23-30. 